\title{
In vivo and in vitro differentiation of male germ cells in the mouse
}

\author{
Orly Lacham-Kaplan \\ Monash Immunology and Stem Cell Laboratories, Monash University, 27-31 Wright Street, Clayton, \\ Victoria 3165, Australia \\ Correspondence should be addressed to Orly Lacham-Kaplan; Email: orly.lacham-kaplan@med.monash.edu.au
}

\begin{abstract}
Primordial germ cells appear in the embryo at about day 7 after coitum. They proliferate and migrate towards the genital ridge. Once there, they undergo differentiation into germ stem cells, known as 'A spermatogonia'. These cells are the foundation of spermatogenesis. A spermatogonia commit to spermatogenesis, stay undifferentiated or degenerate. The differentiation of primordial germ cells to migratory, postmigratory and germ stem cells is dependent on gene expression and cellular interactions. Some of the genes that play a crucial role in germ cell differentiation are Steel, c-Kit, VASA, DAZL, fragilis, miwi, mili, mil1 and mil2. Their expression is stage specific, therefore allowing solid identification of germ cells at different developmental phases. In addition to the expression of these genes, other markers associated with germ cell development are nonspecific alkaline phosphatase activity, the stage specific embryonic antigen, the transcription factor Oct3/4 and $\beta 1$ - and $\alpha 6$-integrins. Commitment of cells to primordial germ cells and to A spermatogonia is also dependent on induction by the bone morphogenetic protein (BMP)-4. With this knowledge, researchers were able to isolate germ stem cells from embryonic stem cell-derived embryoid bodies, and drive these into gametes either in vivo or in vitro. Although no viable embryos were obtained from these gametes, the prospects are that this goal is not too far from being accomplished.
\end{abstract}

Reproduction (2004) 128 147-152

\section{Introduction}

Three studies published in recent months have dramatically changed the outlook on infertility and animal biotechnology, as the message they delivered is that male and female gametes can be produced in vitro from embryonic stem cells (Hubner et al. 2003, Toyooka et al. 2003, Geijsen et al. 2004). All three studies have used embryonic stem cells to establish a population of primordial germ cell-like cells, which, either by transplantation into the testes or by extending cultures, established differentiation into male or female gametes.

The experiments included in these three studies were based on years of thorough investigation of the in vivo development and differentiation of primordial germ cells (PGCs) and germ stem cells (GSCs). By following the path embryonic cells undergo during embryogenesis (Fig. 1), and during pre- and postnatal development to specify as germ cells, researchers have been successful in obtaining sperm and oocytes, as described below.

This review summarizes this path and highlights the most crucial steps embryonic cells undergo to become male germ cells with some references to female germ cells. Markers used to identify PGCs and GSCs during their progress towards spermatogenesis are also detailed.

\section{In vivo differentiation of germ cells}

Following germ cell differentiation through the published literature is rather confusing as to which cell type authors refer to by their specific terminology. Most studies agree that PGCs are the initial cells identified as germ cells. From then on, it becomes a bit confusing. Germ cells before commitment to spermatogenesis are termed premigratory PGCs, postmigratory PGCs, gonocytes, A spermatogonia, GSCs and premeiotic germ cells. In the mouse, PGCs appear at the same time as the three embryonic layers: endoderm, mesoderm and ectoderm. PGCs start migrating from the primitive streak into the allantois and then into the adjacent embryonic endoderm (Anderson et al. 2000). Attempts to identify germ-cell precursor cells at the embryonic stage in mice failed. PGCs are visible around 7 days post-coitum (dpc) in the extraembryonic mesoderm; they migrate through the allantois at $8 \mathrm{dpc}$ to the hindgut and are referred to as migratory PGCs. From the hindgut, they move to reach the gonadal 


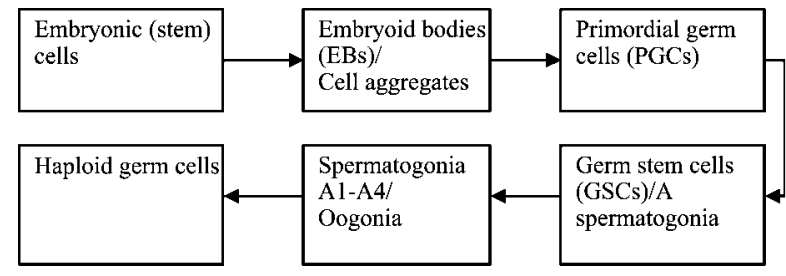

Figure 1 The path that embryonic cells follow during embryogenesis and pre- and postnatal development to specify as germ cells.

ridge at 9.5-11 dpc (Anderson et al. 2000). At this location, they are referred to as postmigratory PGCs. The testis structure is established while the PGCs proliferate and differentiate into gonocytes, which are mitotically quiescent in mice until day 2 after birth. Gonocytes reach the basement membrane of the seminiferous tubuli or remain in the lumen and degenerate. Those that survive differentiate into GSCs, known in the male also as 'A spermatogonia' (De Roij 2001). A spermatogonia undergo multiple cell divisions in stages specified as spermatogonia $\mathrm{A} 1-\mathrm{A} 4$ and differentiation into spermatocytes that continue their meiosis into spermatids. The latter complete their differentiation process into sperm.

The general hypothesis until recently has been that females do not retain GSCs for oogenesis and follicle formation throughout adult life, as males do for spermatogenesis. Recent studies have demonstrated that this hypothesis is not correct. Juvenile mouse and adult mouse and human ovaries possess mitotically active germ cells, allowing continued renewal of the follicle pool in adult ovaries (Bukovsky et al. 2004, Johnson et al. 2004). Hence, it can be postulated that a similar process of germ cell differentiation happens in males and females.

\section{Markers of PGCs and GSCs}

The recent development of microarray expression of data for genes involved in mitosis and meiosis, gamete formation and germline development (Schultz et al. 2003) has enabled the identification of genes that are stage specific to differentiating PGCs and GSCs. The general trend of markers expressed at different stages of PGCs and GSCs is illustrated in Fig. 2. The specification of PGCs involves the synergistic action of bone morphogenetic proteins (BMPs), members of the transforming growth factor type $\beta$ superfamily (Kierszenbaum \& Tres 2001). These proteins bind to receptor complexes signaling to transcription factors to target specific genes. Of this family, BMP4, which is produced from the extraembryonic mesoderm, is associated with PGC formation (Ying \& Zhao 2001). BMP-4 is also produced by Sertoli cells very early in postnatal life, and is downregulated just before puberty (Pellegrini et al. 2003). BMP-4 affects PGCs and oogonia via the $A / k 3$ and the $R$-Smad receptors on these cells (Pellegrini et al. 2003). Therefore, its addition to embryonic stem (ES) cell and to GSC cultures supports their development into differentiated germ cells (Hubner et al. 2003,
Toyooka et al. 2003, Geijsen et al. 2004). At the same time, a putative interferon-inducible gene family, fragilis, fragilis 2 and fragilis 3, code for a transmembrane protein that is apparently associated with the acquisition of germ cell competency by the epiblast cells (Lange et al. 2003). This cluster of genes is expressed in epiblast cells after BMP-4 stimulation. Proliferation of PGCs is gonadotropindependent and is mediated by Akt/PTEN signaling (MoeBehrens et al. 2003).

PGCs express $c$-Kit at relatively high levels. In PGCs as well as in hematopoietic cells, this expression is related to a single DNasel-hypersensitive site (HS2) absolutely necessary for its activity (Cairns et al. 2003). The $c$-Kit proto-oncogene plays a dual role in the control of male fertility in mice via two products. The first $c$-Kit the transmembrane tyrosine kinase receptor for stem cell factor (SCF), which is expressed and functional in differentiating spermatogonia of the postnatal testis. The second, tr-kit, an intracellular protein, which is specifically accumulated during spermatogenesis thorough the use of an alternative intronic promoter, is able to trigger mouse egg activation when injected into mature metaphase II (MII) oocytes. With the onset of meiosis, $c$-Kit expression ceases, and tr-kit is expressed in postmeiotic stages of spermatogenesis, mainly at the early and late spermatid stages (Sandlow et al. 1999). The white spotting locus gene encodes the transmembrane receptor of the cytokine stem cell factor/Kit ligand $(\mathrm{KL})$, which plays an important role as a regulator of proliferation, survival and migration of PGCs (Pesce et al. 1997, Rossi et al. 2000). Estrogen stimulates the Steel gene transcription, increasing the production of $\mathrm{KL}$ and consequently inducing PGC growth (Rossi et al. 2000).

Expression of fragilis is increased in the migratory PGCs, inducing expression of other germ cell-specific genes such as stella (Sato et al. 2002) and the VASA homolog (Mvh) (Toyooka et al. 2000). VASA, which is maintained until postmeiotic germ cells are formed, is a cytoplasmic protein, a product of the VASA homolog $(M v h)$ gene induced by the somatic cells of the genital ridge (Toyooka et al. 2000). Mutation in the Mvh gene leads to deficiency in proliferation and differentiation of PGCs.

Other genes that were identified in PGCs and germ cells belong to the piwi family, miwi and mili, which regulate PGC production and spermatogenesis (Kuramochi-Miyagawa et al. 2001). Two genes, mill and mil2, showing similarities to the human interferon-induced transmembrane protein gene (Ifitm), were also identified in PGCs (Tanaka \& Matsui 2002). mil1 starts to be expressed continuously in differentiating PGCs at about $6.5-7.5 \mathrm{dpc}$, and mil2 expression appears in gonadal PGCs during differentiation at about 9.5-13.5 dpc.

Members of the deleted in azoospermia (DAZ) gene family, which are also used as markers for germ cell identification, are expressed exclusively in germ cells. One of the protein products of the $D A Z L$ gene is 


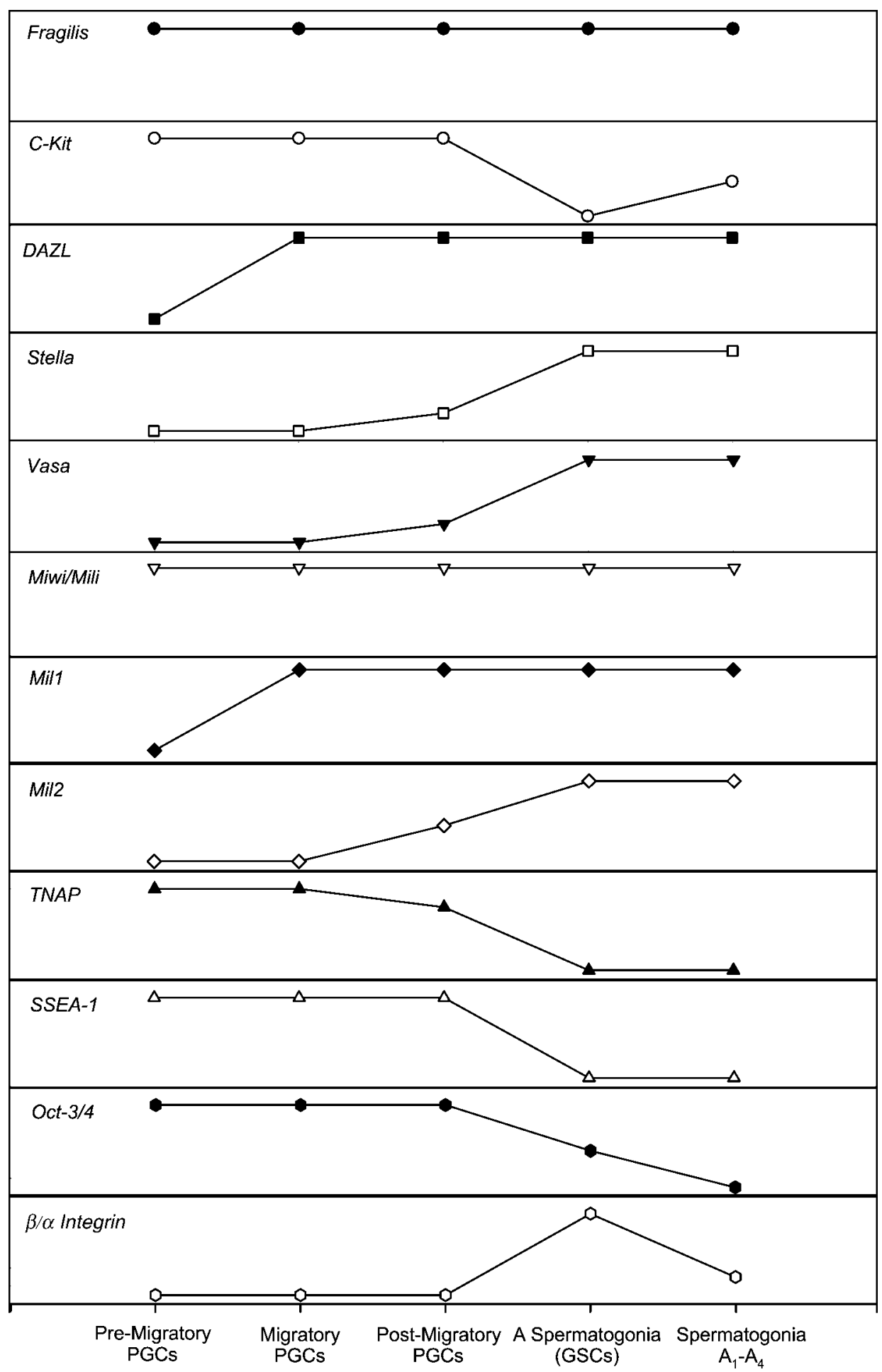

Figure 2 A general description of PGC- and GSC-specific marker expression during their development. The graphs demonstrate a trend only and do not represent quantity. Points marked at the bottom of the box represent zero or very low expression. Points marked at the top part of the box represent high expression.

expressed throughout most of the life of germ cells and is required for the development of PGCs and for the differentiation and maturation of germ cells from PGCs onwards (Yen 2004).
It has been also found that PGCs have a high level of tissue nonspecific alkaline phosphatase (TNAP) activity (MacGregor et al. 1995). However, it is not clear whether this activity is required for the survival of these cells. 
Other markers for PGCs include the stage-specific embryonic antigen (SSEA1) (Fox et al. 1981), and the transcription factor Oct3/4 (Yeom et al. 1996). PGCs are the only cells expressing Oct3/4 after postgastrulation, which has a role in their totipotent phenotype (Pesce \& Scholer 2000).

The differentiation of PGCs into GSCs results in a marked change in markers, including a decrease in alkaline phosphatase activity and a decrease in C-Kit and SSEA-1 expression (Sandlow et al. 1999). GSCs gain additional surface markers such as $\beta 1$ - and $\alpha 6$-integrin (Shinohara et al. 1999). C-Kit expression appears again in differentiated spermatogonia A (Sandlow et al. 1999).

The arrival of PGCs in the genital ridge stimulates proliferation of other epithelial and mesenchyme cells to form the undifferentiated gonad composed of two compartments. The first is that of epithelial cells containing the PGCs, and the other is a stromal compartment containing fibroblasts and blood vessels. A morphologic distinction in female and male gonads is obvious about $12-12.5 \mathrm{dpc}$. Although a few genes that appear in both male and female gonads have been connected to gonadal establishment and sex differentiation (Merchant-Larios \& MorenoMendoza 2003), attention has been given to the Sry gene located at the $Y$ chromosome (Koopman et al. 1990). The exact pathway by which Sry affects differentiation to a male gonad is elusive and is probably an outcome of gene expression and cellular interactions. Following sex determination, male germ cells enter a mitotic arrest that is maintained until after birth. Female germ cells enter meiotic prophase. Recently, the Stra 8 gene has been identified as an early molecular marker of female germ cell differentiation (Menke et al. 2003). This gene is upregulated in germ cells of XX gonads prior to meiotic entry and is not expressed in male embryonic germ cells. This is in conjunction with upregulation of the meiotic gene Dmc1 and downregulation of Oct 3/4.

\section{From embryonic stem (ES) cells to gametes in vitro}

Restoration of a complete spermatogenesis process in culture is important to understand the biologic events related to cell proliferation and cell differentiation. Even more important is the hope of providing a treatment to many infertile individuals. Cocultures of germ cells with Sertoli cells aid a limited number of cells to undergo meiosis and become round spermatids (Parks et al. 2003). The latter can be directly injected into oocytes to result in viable embryos and live offspring (Kimura \& Yanagimachi 1995, Parks et al. 2003). However, a critical requirement for successful in vitro spermatogenesis is maintaining germcell viability in vitro for long periods of time, and this implies greater limitations on initiation of spermatogenesis from PGCs or GSCs. To examine the ability of PGCs to progress through spermatogenesis, researchers have been concentrating on developing methods to enrich this cell population in vivo and in vitro (McCarrey et al. 1987,
DeFelici 1998, Mayanagi et al. 2003a,b) in conjunction with the optimization of prolonged culture systems. Mouse PGCs are generally difficult to maintain in vitro for longer than a week even when cultured within urogenital complexes. Longer maintenance of these complexes and an increase in PGC number has been accomplished by the replacement of bovine and equine serum with rodent serum (Mayanagi et al. 2003b). Interestingly, more PGCs can be obtained when gonads originate from male mice. Studies have also shown that $17 \beta$-estradiol (E2) or mycoestrogen zearalnone (ZEA) significantly increase, in a dose-dependent manner, the number of PGCs cultured on STO fibroblasts in the presence of gonadal somatic cells (Moe-Behrens et al. 2003).

Methods to separate GSCs from testicular tissue and maintain them for prolonged periods in vitro have been also explored (Kanatsu-Shinohara et al. 2003, Nagano et al. 2003). As they are a rare cell population within the testis, enrichment (McLean et al. 2002 2003, Shinohara et al. 2000a) and identification (Schrans-Stassen 1999, Shinohara et al. 1999 2000b, Van der Wee et al. 2001) of GSCs are imperative. A purified population of A spermatogonia may survive a prolonged culture period when cocultured on monolayers of Sertoli cells producing stem cell factor (SCF) (Van der Wee et al. 2001, Feng et al. 2002). In vitro addition of SCF to c-Kit-expressing $A(1)-A(4)$ spermatogonia from prepubertal mice, or to immortal A spermatogonia (Feng et al. 2002), stimulates their progression into the mitotic cell cycle and significantly reduces apoptosis in these cells (Yan et al. 2000, Dolci et al. 2001).

The use of PGCs and GSCs in transplantation studies to restore fertility has been initiated with varied degrees of success (Parks et al. 2003, Nayernia et al. 2004), leading scientists to push boundaries even further by using ES cells as the starting point for germ cell differentiation. Embryoid bodies (EBs), established from ES cells, consist of tissue lineages typical of the early embryo. Recently, researchers have been able to show that mouse and human ES cellderived EBs include cells that express markers specific to germ cells (Hubner et al. 2003, Toyooka et al. 2003, Clark et al. 2004, Geijsen et al. 2004). In two separate studies, scientists succeeded in isolating these spontaneously differentiated cells and driving their development further in spermatogenesis in vivo or in vitro. Toyooka et al. (2003) isolated PGCs from male knock-in embryonic stem cells in which GFP or LacZ was inserted adjacent to the VASA gene homolog. Cells expressing GFP or LacZ also expressed $M v h$, indicating their differentiation into germ stem cells. The appearance of these cells was observed in 5-7-day-old Ebs, and their concentration increased after exposure to BMP-4 secreted by trophectoderm cells. After isolation and transplantation into testicular tubuli, these cells were able to progress in spermatogenesis and produce fully differentiated sperm.

In the second study, spermatogenesis up to haploid cells was accomplished in vitro (Geijsen et al. 2004). 
Like Toyooka et al. (2003), Geijsen et al. (2004) also isolated germ cells from EBs. Addition of retinoic acid to these EBs resulted in manifestation of a cell population with positive SSEA-1 expression that stained positive for alkaline phosphatase, indicating them to be PGC-like cells. The in vitro differentiation of germ cells identified by Geijsen et al. (2004) was confirmed by the positive expression of markers such as Oct3/4 Piwil2 and DAZL. The Sry gene, specific to the male germ cell, was also expressed in some of the cells. This specification to a male germline was confirmed by the identification of upregulation of acrosin and heparin in the highly specified cells, suggesting that the default phenotype of female germ cells was suppressed in their cultured EBs. The differentiated cells underwent limited meiosis to produce a small number of haploid cells. These cells were able to fertilize mature oocytes by intracytoplasmic injection, and $20 \%$ of the embryos developed to blastocysts in vitro.

In another study (Hubner et al. 2003), oocytes were obtained in vitro from male or female ES cells with no specific or significant modification to culture conditions, suggesting that germ-cell differentiation from ES cells is a spontaneous event. It can be postulated that the observations in this study were detected purely because of the extended culture time of 26 days, not previously used by other researchers. Hubner and colleagues (2003) used ES cells with a restricted germ cell Oct3/4 and GFP marker for their study. These cells were cultured in a common ES culture medium. After 4 days, germ cell-specific Oct3/4 was detected in some cells. About $40 \%$ of cells expressed germ cell Oct3/4 at 7 days in culture. These cells were separated from the rest and were examined for the expression of $c$-Kit and VASA. Three germ cell-type cells were identified: 1) cells positive for Oct3/4 and c-Kit with little expression of VASA that resemble premigratory germ cells (PGCs); 2) cells expressing Oct3/4 and VASA, but not $C-K i t$, that resemble early postmigratory germ cells (PGCs and gonocytes); 3 ) cells with negative Oct3/4 expression, negative for c-Kit expression and positive for VASA expression, that resemble postmigratory cells about to enter prophase I. Although, in this study, ES cells were not allowed to form EBs in culture, defined aggregates formed during the extended culture time were collected and cultured in new plates. These formed structures were similar to ovarian follicles producing oocytes. Hubner et al. (2003) proposed that male and female ES cells develop into germ cells with the female phenotype because of the absence of appropriate Sry expression. This lack of Sry expression may have been affected by the lack of appropriate stimulant for the production of male germ cells. In relation to the other two studies, this may be BMP-4 and/or retinoic acid. The oocytes underwent spontaneous activation and formed blastocysts.

These three recent studies have proved that gametes can be obtained in culture, and that the prospect of overcoming all types of sterility is more realistic than was thought. The fact that no viable embryos were produced in any of these studies has raised speculation regarding the future of such developments. It is now remains to determine whether germ cells produced in vitro are capable of producing healthy offspring.

\section{References}

Anderson A, Copel TK, Scholer H, Heasman J \& Wylie C 2000 The onset of germ cell migration in the mouse embryo. Mechanism of Development 91 61-68.

Bukovsky A, Caudle MR, Svetlikova M \& Upadhyaya NB 2004 Formation of new primary follicles in adult human ovaries. Reproductive Biology and Endocrinology 2 20-32.

Cairns LA, Moroni E, Levantini E, Giorgetti A, Clinger FG, Ronzoni S, Tatangelo L, Tiveron C, DeFelici M, Dolci S, Magli MC, Giglioni B \& Ottolenghi S 2003 Kit regulatory elements required for expression in developing hematopoietic and germ cell linages. Blood 102 3954-3962.

Clark AT, Bodnar MS, Fox M, Rodriquez RT, Abeyta MJ, Firpo MT \& Pera RAR 2004 Spontaneous differentiation of germ cells from human embryonic stem cells in vitro. Human Molecular Genetics $13727-739$.

DeFelici M 1998 Isolation and culture of germ cells from the mouse embryo. In Cell Biology, a Laboratory Handbook, 2nd edn, vol 1, pp 73-85. Ed. J Celis. Burlington, VT: Academic Press.

De Roij DG 2001 Proliferation and differentiation of spermatogonial stem cells. Reproduction 121 347-354.

Dolci S, Pellegrini M, Di Agostino S, Geremia R \& Rossi P 2001 Signalling through extracellular signal-regulated kinase is required for spermatogonial proliferative response to stem cell factor. Journal of Biology and Chemistry 276 40225-40233.

Feng LX, Chen Y, Dettin L, Pera RAR, Herr JC, Goldberg E \& Dym M 2002 Generation and in vitro differentiation of a spermatogonial cell line. Science 297 392-395.

Fox M, Damjanov I, Martinez-Hernandez A, Knowles BB \& Solter D 1981 Immunohistochemical localization of the early embryonic antigen (SSEA-1) in post-implantation mouse embryos and fetal and adult tissues. Developmental Biology 83 391-398.

Geijsen N, Horoschak M, Kim K, Gribnau J, Eggan K \& Daley GQ 2004 Derivation of embryonic germ cells and male gametes from embryonic stem cells. Nature 427 148-154.

Hahnel AC, Rappolee DA, Millan JL, Manes T, Ziomek CA, Theodosiou NG, Werb Z, Pederson RA \& Schultz GA 1990 Two alkaline phosphatase genes are expressed during early development in the mouse embryo. Development 110 555-564.

Hubner K, Fuhrmann G, Christenson LK, Kehler J, Reinbold R, de la Fuente R, Wood J, Strauss JF III, Boiani M \& Scholer HR 2003 Derivation of oocytes from embryonic stem cells. Science $3001251-1256$.

Johnson J, Canning J, Kaneko T, Pru JK \& Tilly JL 2004 Germline stem cells and follicular renewal in the postnatal mammalian ovary. Nature 428 145-150.

Kanatsu-Shinohara, Ognuki N, Miki H, Ogura A, Toyokuni S \& Shinohara T 2003 Long term proliferation in culture and germline transmission of mouse male germline stem cells. Biology of Reproduction $69612-616$.

Kierszenbaum A \& Tres LL 2001 Primordial germ cell-somatic cell partnership: a balancing cell signalling act. Molecular Reproduction and Development 60 277-280.

Kimura Y \& Yanagimachi R 1995 Mouse oocytes injected with testicular spermatozoa or round spermatids can develop into normal offspring. Development 121 2397-2405.

Koopman P, Munsterberg A, Capel B, Vivian N \& Lovell-Badge R 1990 Expression of a candidate sex-determining gene during mouse testis differentiation.

Kuramochi-Miyagawa S, Kimura T, Yomogida K, Kuroiwa A, Tadokoro Y, Fujita Y, Sato M, Matsuda Y \& Nakano T 2001 Two 
mouse piwi-related genes: miwi and mili. Mechanism of Development 108 121-133.

Lange UC, Saitou M, Western PS, Barton SC \& Surani MA 2003 The fragilis interferon-inducible gene family of transmembrane proteins is associated with germ cell specification in mice. Developmental Biology 3 1-11.

Li H \& Kim KH 2004 Retinoic acid inhibits rat XY gonad development by blocking mesonephric cell migration and decreasing the number of gonocytes. Biology of Reproduction 70 687-693.

MacGregor GR, Zambrowicz BP \& Soriano P 1995 Tissue nonspecific alkaline phosphatase is expressed in both embryonic and extraembryonic lineages during mouse embryogenesis but is not required for migration of primordial germ cells. Development 121 1487-1496.

Mayanagi T, Kurosawa R, Ohnuma K, Ueyama A, Ito K \& Takahashi J 2003a Purification of mouse primordial cells by Nycodenz. Reproduction 125 667-675.

Mayanagi T, Ito K \& Takahashi J 2003b Association of culture of mouse urogenital complexes in media containing rodent sera with the appearance of primordial germ cell-like cells. Reproduction 12 519-526.

McCarrey JR, Hsu KC, Eddy EM, Klevecz RR \& Bolen JL 1987 Isolation of viable mouse primordial germ cells by antibody-directed flow sorting. Journal of Experimental Zoology 242 107-111.

McLean DJ, Russell LD \& Griswold MD 2002 Biological activity of spermatogonial stem cells in vitamin A-deficient and hyperthermia-exposed testes from mice based on colonization following germ cell transplantation. Biology of Reproduction 66 1374-1379.

McLean DJ, Friel PJ, Johnston DS \& Griswold MD 2003 Characterization of spermatogonial stem cell maturation and differentiation in neonatal mice. Biology of Reproduction 69 2085-2091.

Menke DB, Koubova J \& Page DC 2003 Sexual differentiation of germ cells in XX mouse gonads occurs in an anterior-to posterior wave. Developmental Biology 262 303-312.

Merchant-Larios H \& Moreno-Mendoza N 2003 Onset of sex differentiation: dialog between genes and cells. Archives of Medical Research 32 553-558.

Moe-Behrens GHG, Klinger FG, Eskild W, Grotmol T, Haugen TB \& DeFelici M 2003 Akt/PTEN signalling mediates estrogen-dependent proliferation of primordial germ cells in vitro. Molecular Endocrinology 17 2630-2638.

Nagano M, Ryu BY, Brinster CJ, Avarbock MR \& Brinster RL 2003 Maintenance of mouse male germline stem cells in vitro. Biology of Reproduction 68 2207-2214.

Nayernia K, Li M, Jaroszynski L, Khusainov R, Wulf G, Schwandt I, Korabiowska M, Michelmann HW, Meinhardt A \& Engel W 2004 Stem cell-based therapeutical approach of male infertility by teratocarcinoma derived germ cells. Human Molecular Genetics.

Parks JE, Lee DR, Huang S \& Kaproth MT 2003 Prospects for spermatogenesis in vitro. Theriogenology 59 73-86.

Pellegrini M, Grimaldi P, Rossi P, Geremia R \& Dolci S 2003 Developmental expression of BMP4/ALK3/SAMD5 signalling pathway in the mouse testis: a potential role of BMP4 in spermatogonia differentiation. Journal of Cell Sciences 116 3363-3372.
Pesce M \& Scholer HR 2000 Oct-4 control of totipotency and germline determination. Molecular Reproduction and Development $\mathbf{5 5}$ 452-457.

Pesce M, Di Carlo A \& Defelici M 1997 The c-kit receptor is involved in the adhesion of mouse primordial germ cells to somatic cells in culture. Mechanisms of Development 68 37-44.

Rossi P, Sette C, Dolci S \& Geremia R 2000 Role of c-kit in mammalian spermatogenesis. Journal of Endocrinology Investigation 23 609-615.

Sandlow JI, Feng HL, Zheng LJ \& Sandra A 1999 Migration and ultrastructural localization of the c-kit receptor protein in spermatogenic cells and spermatozoa of the mouse. Journal of Urology 161 $1676-1680$.

Sato M, Kimura T, Kurokawa K, Fujita $Y$, Abe K, Masuhara M, Tasunaga T, Ryo A, Yamamoto M \& Nakano T 2002 Identification of PGC7, a new gene expressed specifically in preimplantation embryos and germ cells. Mechanisms of Development 113 91-94.

Schultz N, Hamra FK \& Garbers DL 2003 A multitude of genes expressed solely in meiotic or postmeiotic spermatogenic cells offers a myriad of contraceptive targets. PNAS 100 12201-12206.

Shinohara T, Avarbock MR \& Brinster RL 2000a Functional analyses of spermatogonial stem cells in Steel and cryptorchid infertile mouse models. Developmental Biology 220 401-411.

Shinohara T, Orwig KE, Avarbock MR \& Brinster RL 2000 b Spermatogonial stem cell enrichment by multiparameter selection of mouse testis cells. PNAS 97 8346-8351.

Schrans-Stassen BH, van de Kant HJ, de Rooij DG \& van Pelt AM 1999 Differential expression of c-kit in mouse undifferentiated and differentiated type A spermatogonia. Endocrinology $\mathbf{1 4 0}$ $5894-5900$.

Tanaka SS \& Matsui Y 2002 Developmentally regulated expression of mil-1 and mil-2, mouse interferon-induced transmembrane protein like gene, during formation and differentiation of primordial germ cell. Gene Expression Patterns 2 297-303.

Toyooka Y, Tsunekawa N, Takahashi Y, Matsui Y, Satoh M \& Noce T 2000 Expression and intracellular localization of mouse vasa-homologue protein during germ cell development. Mechanisms of Development 93 139-149.

Toyooka Y, Tsunekawa N, Akasu R \& Noce T 2003 Embryonic stem cells can form germ cells in vitro. PNAS 100 11457-11462.

Van der Wee KS, Johnson EW, Dirami G, Dym TM \& Hofmann MC 2001 Immunomagnetic isolation and long term culture of mouse type A spermatogonia. Journal of Andrology 22 696-704.

Yan W, Suminen J \& Toppari J 2000 Stem cell factor protects germ cells from apoptosis in vitro. Journal of Cell Sciences 113 $161-168$.

Yen PH 2004 Putative biological functions of the DAZ family. International Journal of Andrology 27 125-129.

Yeom YI, Fuhrmann G, Ovitt CE, Brehm A, Ohbo K, Gross M, Hubner K \& Scholer HR 1996 Germline regulatory element of Oct-4 specific for the totipotent cycle of embryonic cells. Development 122 881-894.

Ying Y \& Zhao GQ 2001 Cooperation of endoderm-derived BMP2 and extraembryonic ectoderm-derived BMP4 in primordial germ cell generation in the mouse. Developmental Biology 232 484-492. 